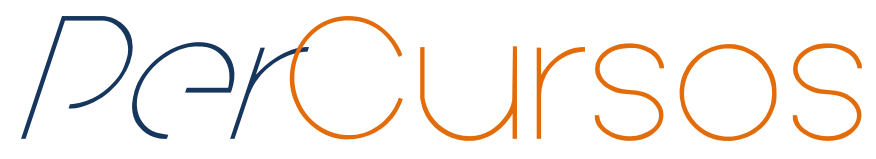

\title{
Programa institucional de bolsa de iniciação à docência: perspectivas e desafios no âmbito do subprojeto do curso de pedagogia da UFV
}

\begin{abstract}
Resumo
Este artigo é a comunicação do resultado de uma pesquisa desenvolvida no ano de 2015 na Universidade Federal de Viçosa (UFV) que procurou identificar e analisar os principais desafios enfrentados no âmbito do Programa Institucional de Bolsa de Iniciação à Docência (PIBID), com recorte no subprojeto do curso de Pedagogia. Mais especificamente, o trabalho buscou investigar as possíveis dificuldades enfrentadas pelas pessoas que atuavam no Programa: 63 estudantes e três docentes coordenadores do Subprojeto. Além disso, buscou-se listar e compreender os caminhos que essas pessoas percorreram para amenizar e/ou superar seus desafios. Como referencial teórico, o trabalho possui duas chaves de leitura. Por um lado, inscreve-se no campo da Formação Docente (GATTI, NUNES, 2009; GATTI, BARRETO, ANDRÉ, 2011) ao buscar conhecer a identidade e a trajetória formativa e/ou profissional das pessoas envolvidas no Programa. Por outro, o trabalho recorre ao campo dos Estudos Culturais (JOHNSON, 1999; NELSON et al., 2003), com foco no conceito de experiência (BONDÍA, 2012), ao ouvir os sujeitos atuantes. De caráter qualitativo, a pesquisa fez uso de procedimentos metodológicos que incluíram instrumentos de produção de dados. O desenho utilizou uma amostra de $10 \%$ da população de bolsistas de iniciação à docência que responderam aos questionários, além da participação de três dos quatro professores coordenadores de área que foram entrevistados. $O$ argumento central do trabalho é o de que o PIBID, visando à valorização do magistério e à integração entre a educação básica e universidade, pode representar importante veículo formativo que precisa ser mais bem analisado e compreendido.
\end{abstract}

Palavras-chave: Formação Docente. Experiência Docente. Programa Institucional de Bolsa Iniciação à Docência.
Flávia de Castro Almeida

Graduada em Pedagogia pela

Universidade Federal de Viçosa -

UFV. Professora no Ensino

Fundamental I do Colégio Anglo

de Viçosa-MG.

Brasil

flavia.c.almeida@ufv.br

Frederico Assis Cardoso

Doutor em Educação pela

Universidade Federal de Minas

Gerais - UFMG. Professor da

Universidade Federal de Minas

Gerais - UFMG.

Brasil

fredasc@ufmg.br

\footnotetext{
Para citar este artigo:

ALMEIDA, Flávia de Castro; CARDOSO, Frederico Assis. Programa institucional de bolsa de iniciação à docência: perspectivas e desafios no âmbito do subprojeto do curso de pedagogia da UFV. Revista PerCursos, Florianópolis, v. 19, n.39, p. 240 - 265, jan./abr. 2018.
}

DOI: $\mathbf{1 0 . 5 9 6 5 / 1 9 8 4 7 2 4 6 1 9 3 9 2 0 1 8 2 4 0}$

http://dx.doi.org/10.5965/1984724619392018240 


\title{
Institutional Program of the Initiation to Teaching Grant: perspectives and challenges in the context of the subproject of the Pedagogy Course of UFV
}

\begin{abstract}
This article is the communication of the results of a research conduct in the year 2015 at the Federal University of Viçosa (UFV), which sought to identify and analyze the main challenges faced in the Institutional Program of the Initiation to Teaching Grant (PIBID), with a subproject of the Pedagogy course. More specifically, the work sought to investigate the possible difficulties faced by the people who worked in the Program: 63 students and three coordinating teachers of the Subproject. In addition, we sought to list and understand the paths that these people traveled to ease and / or overcome their challenges. As a theoretical reference, the work has two reading keys. On the one hand, it is part of the field of Teacher Education (GATTI, NUNES, 2009; GATTI, BARRETO, ANDRÉ, 2011), seeking to know the identity and the training and / or professional trajectory of the people involved in the Program. On the other hand, the work uses the field of Cultural Studies (JOHNSON, 1999; NELSON et alii, 2003), focusing on the concept of experience (LARROSA, 2012), when listening to the acting subjects. Of qualitative character, the research made use of methodological procedures that included instruments of data production. The drawing used a sample of $10 \%$ of the population of scholarship recipients who answered the questionnaires, in addition to the participation of three of the four area coordinators who were interviewed. The main argument of the work is that PIBID, aiming at the valorization of teaching and the integration between basic education and university, can represent an important formative vehicle that needs to be better analyzed and understood.
\end{abstract}

Keywords: Teacher Training. Teaching Experience. Institutional Scholarship Initiation Program. 


\section{Introdução: apresentação geral da pesquisa}

O ambiente escolar pode ser campo fértil de trocas de conhecimentos, de experiências, de valores, de leituras de mundo e modos de vida. Essas características podem ser facilmente percebidas por qualquer sujeito, mas são as pessoas inseridas no interior desse ambiente quem vivenciam a dor e a delícia de estar envoltos por esse universo tão instável, onde as mais diversas situações podem vir à tona a qualquer momento.

Nesse contexto, este trabalho teve o intuito de analisar e conhecer os principais desafios encontrados pelos sujeitos envolvidos no universo escolar a partir de suas experiências no Programa Institucional de Bolsa de Iniciação à Docência (PIBID), entre eles bolsistas estudantes de Licenciatura em Pedagogia e professores coordenadores do subprojeto do mesmo Curso na Universidade Federal de Viçosa (UFV). Ao longo do trabalho foram abordadas questões acerca do tema, buscando compreender quais seriam as principais implicações dessa política no universo escolar.

O estudo consistiu, então, em identificar os principais desafios enfrentados no trabalho realizado por meio do Programa nas escolas atendidas na cidade de Viçosa/MG. Mais especificamente visando pesquisar as possíveis dificuldades enfrentadas pelos bolsistas, identificar os desafios encontrados pelos coordenadores do Subprojeto e, por fim, listar e compreender os caminhos que esses sujeitos percorriam para amenizar e/ou superar tais desafios. Para tanto, como embasamento teórico, fizemos uso das contribuições de estudos produzidos no campo da Formação Docente, abordando conceitos como identidade docente, representação profissional e trajetória formativa (GATTI, NUNES, 2009). Além disso, produzimos em diálogo com o campo dos Estudos Culturais, tendo como foco o conceito de experiência elaborado por Bondía (2002).

De caráter qualitativo, a pesquisa adotou como procedimentos metodológicos instrumentos de produção de dados como questionários, aplicados a 10\% dos estudantes bolsistas, e entrevistas realizadas com 03 professores coordenadores de área do Subprojeto Pedagogia. Isso nos permitiu construir um perfil de configuração dos sujeitos 
envolvidos no PIBID-Pedagogia. Parte dos resultados dos registros e dos depoimentos encontra-se documentada neste trabalho.

\section{Traços do desenho da investigação: aspectos teórico-metodológicos}

Por estarem vinculados à UFV e em atuação no PIBID-Pedagogia no momento da pesquisa, os autores do texto escolheram, como sujeitos, discentes e docentes participantes do Programa. Esta escolha, obviamente intencional, permitiu acessar os sujeitos investigados de forma mais fácil e rápida. Contudo, esta não foi apenas uma escolha de ordem prática. Buscamos esses sujeitos por entendermos que a partir do momento em que o PIBID, como uma política pública, visa à valorização do magistério e à melhoria da educação pública no Brasil, torna-se necessário conhecer quais são os impasses encontrados no trabalho desenvolvido, bem como quais são as estratégias traçadas pelos sujeitos envolvidos na busca por superar ou ao menos amenizar essas dificuldades.

Nesse contexto, optamos por uma metodologia de pesquisa qualitativa, por não estarmos preocupados com a representatividade expressiva dos dados, mas sim com o seu caráter significativo para compreensão do fenômeno em estudo. Conforme Minayo (1994):

A pesquisa qualitativa responde a questões muito particulares. Preocupase com um nível de realidade que não pode ser quantificado. Ou seja, ela trabalha com um universo de significados, motivações, aspirações, crenças, valores e atitudes, o que corresponde a um espaço mais profundo das relações, dos processos e dos fenômenos que não podem ser reduzidos à operacionalização de variáveis. (MINAYO, 1994, p. 21).

Araújo e Borba (2004, p. 40) evidenciam que “[...] quando decidimos desenvolver uma pesquisa, partimos de uma inquietação inicial e, com algum planejamento, não muito rígido, desencadeamos um processo de busca". Sendo assim, a busca pela construção dos dados foi, primeiramente, baseada em uma análise documental sobre o PIBID; 
depois, em buscas na literatura, tanto aquela referente à Formação Docente, como aquela sobre os Estudos Culturais. Esse investimento teve como objetivo conhecer a origem do PIBID, sua função, suas finalidades, seu surgimento e seus idealizadores. Da mesma forma, buscamos conhecer a história do Programa por meio de pesquisas já realizadas sobre o tema e a análise de seus respectivos documentos. De acordo com Luna (1999), essa coleta de dados possibilita um apanhado geral sobre os principais trabalhos desenvolvidos sobre determinado assunto, sendo, portanto, fonte de informações relevantes para novos estudos. Nesse primeiro momento as leituras foram fundamentais para embasar a continuidade do trabalho. Além disso, também foram realizadas leituras nos campos da Formação Docente e dos Estudos Culturais. Neste trabalho, destacamos como elo condutor dessas duas chaves de leitura o conceito de experiência, tal como produzido por Bondía (2002), que o definiu como

[...] um encontro ou uma relação com algo que se experimenta, que se prova. [...] A experiência é a passagem da existência, a passagem de um ser que não tem essência ou razão ou fundamento, mas que simplesmente "ex-iste" de uma forma sempre singular, finita, imanente, contingente. (BONDÍA, 2002, p. 25).

Para nós, o ambiente escolar se revelou de grande valia como cenário para uma pesquisa que necessitava conhecer as experiências diárias de seus sujeitos. Buscávamos compreender como as práticas poderiam influenciar os resultados escolares, um dos parâmetros para testar a eficiência e eficácia de um Programa criado em âmbito nacional com a finalidade principal de incentivar a formação docente em busca da melhoria da qualidade na educação básica brasileira.

Para além do conceito de Jorge Larrosa Bondía - para quem a experiência guarda a noção de aquilo que toca, aquilo que provoca, o que convoca e mobiliza os sujeitos, fruto da reflexão sobre o que passa com as pessoas - trabalhamos também com os conceitos de identidade e trajetória, fundamentais para compreender melhor quais as significações atribuídas ao trabalho desenvolvido pelas pessoas envolvidas no PIBID. Assim, adotamos como trajetória a ideia de caminho percorrido, de passagem, com ênfase nos desafios 
encontrados pelos depoentes. No que diz respeito à identidade, consideramos a descrição de que ela se estabelece como "uma construção histórica que cada indivíduo ou grupo social elabora ao longo de suas experiências, de acordo com especificidades do contexto e das condições sociais que vivenciam" (CARDOSO, 2004, p. 16).

A escola é o espaço social em que as mais diversas trajetórias se esbarram, ação que pode estabelecer relações de aprendizagens, de encontros e de socializações; portanto, o contato com esse local durante a formação docente é fundamental para familiarizar o futuro docente com situações que farão parte de seu cotidiano, dando-lhe então condições de refletir sobre como tratar determinados eventos baseados em experiências já vividas. Tendo em vista a universalização do ensino que, cada vez mais, traz para a escola os mais diversos alunos, sujeitos de diferentes origens culturais, econômicas, históricas e sociais, pessoas de diferentes demandas, necessidades ou valores, os professores, bem como o conjunto da comunidade escolar, precisam estar cada vez mais preparados para lidar com esse cenário, ficando a preparação enraizada nas próprias experiências, pessoais e sociais, próprias da dinâmica educativa. Para Gatti, Barreto e André (2011) essa nova situação no cenário educacional

[...] solicita, cada vez mais, que esse(a) profissional esteja preparado(a) para exercer uma prática contextualizada, atenta às especificidades do momento, à cultura local, ao alunado diverso em sua trajetória de vida e expectativas escolares. Uma prática que depende não apenas de conhecimentos e de competências cognitivas no ato de ensinar, mas também de valores e atitudes favoráveis a uma postura profissional aberta, capaz de criar e ensaiar alternativas para os desafios que se apresentam. (GATTI, BARRETO e ANDRÉ, 2011 p. 25).

O fato de que, futuramente, bolsistas do Programa irão trabalhar com essa realidade tão diversa só reforça que é necessário estar cada vez mais atento às especificidades; o que pode ser compreendido a partir da observação e da reflexão do contexto escolar, a fim de fugirmos da homogeneização e da massificação dos alunos. Esse processo de observação faz parte da trajetória do professor, pois é por meio dela que o docente pode conhecer mais profundamente seus alunos, as suas necessidades e 
habilidades, estabelecendo assim uma prática reflexiva, atenta a um processo de investigação na ação, onde se aprende fazendo e refletindo na e sobre a prática (SCHÖN, 2000).

Tal como ocorre com os alunos, o docente também não é uma folha em branco. As suas experiências, tanto pessoais como formativas/profissionais, sua trajetória e suas representações, constituem e ajudam a inaugurar parte de sua identidade. Logo, ele carrega consigo marcas adquiridas ao longo da toda a sua vida social; um conjunto de saberes que o habitam e que são usados no desenvolvimento de suas ações no ambiente escolar. Portanto, é necessário entender que a construção da identidade do docente não acontece apenas nos cursos de formação, mas abarca toda situação já experimentada por ele, algo que o antecede e que o ultrapassa.

Compreendendo a identidade como uma construção histórica, elaborada ao longo de experiências e de acordo com especificidades de condições situacionais e sociais que vivenciamos (CARDOSO, 2004), percebemos o professor como um sujeito sempre em construção, tendo seu conhecimento definido por Freire (1996, p. 24) como "um conjunto de saberes teóricos e experienciais que se expressam, portanto, em um saber agir conforme a situação e em conformidade com o contexto do indivíduo".

Foi a compreensão do estudo do referencial teórico que nos permitiu estabelecer contato com os sujeitos dessa pesquisa de forma mais intimista, na medida em que nos aproximamos de pessoas e de temáticas que já conhecíamos. O convite inicial às pessoas ligadas ao Subprojeto Pedagogia ocorreu por meio de correio eletrônico e realizamos, nos meses de setembro e de outubro de 2015, a aplicação de questionários online. Os questionários foram estruturados com treze questões que versavam sobre as atividades realizadas no Programa, as dificuldades e as perspectivas dos estudantes bolsistas em relação às suas experiências no PIBID. Nesta etapa nos dedicamos exclusivamente ao trabalho com os bolsistas de iniciação à docência. No total, o PIBID-Pedagogia contava com 64 licenciandos ${ }^{1}$.

\footnotetext{
${ }^{1} \mathrm{Na}$ ocasião de nossa pesquisa, o Subprojeto de Pedagogia possuía quatro professores coordenadores. Cada um deles atuava junto a um grupo de aproximadamente 16 bolsistas de graduação em atendimento a cerca de 02 escolas públicas para cada grupo. Cada escola contava ainda com 01 professor da educação
} 
Segundo Malhotra (2006), as pesquisas realizadas com o auxílio de meios eletrônicos e digitais, feitas majoritariamente pela Internet, estão ficando cada vez mais populares entre os pesquisadores, principalmente devido às suas vantagens, entre as quais estariam: os menores custos, a rapidez de contato e a capacidade de atingir populações específicas. Do ponto de vista do sujeito respondente, a possibilidade de contribuir da maneira que lhe for mais conveniente, no tempo e local de sua escolha. Dessa forma o contato por meio desse veículo de comunicação se mostrou mais eficaz, tendo em vista o tamanho da população pesquisada e a dificuldade de encontrar com cada um desses sujeitos pessoalmente em datas, locais e horários específicos. Cabe salientar que, infelizmente, devido às condicionantes acadêmicas, foram escassos os momentos formativos capazes de congregar o conjunto de 64 estudantes bolsistas e os quatro professores coordenadores. Em cerca de dois anos de Programa esses momentos ocorreram apenas três vezes, sempre no início ou no término do semestre letivo da Universidade. Outros fatores determinantes que impossibilitavam a maior frequência dos momentos formativos eram as agendas de bolsistas, coordenadores e professores da educação básica, estudantes e docentes de atuação em diferentes turnos de trabalho, bem como os aspectos de logística que envolviam espaços e condições adequadas e a incompatibilidade, em alguns casos fruto de movimentos próprios das diferentes instituições de ensino, a escola e a universidade, de calendários letivos correspondentes².

Sobre o uso de questionários como procedimento metodológico, Quivy e Campenhoudt (1995, p. 186) afirmam que o instrumento consiste em um método de colocar questões a um grupo representativo da população. Podem ser “de administração indireta" quando é o próprio pesquisador a preenchê-lo, a partir das respostas dadas pelo

básica como referência de tutoria para os estudantes licenciandos. Assim, a população total de discentes bolsistas era composta por 64 pessoas. Entretanto, não estiveram submetidos aos protocolos de pesquisa uma bolsista e um professor coordenador, devido ao fato de esses serem os proponentes do presente trabalho, dessa forma apenas 63 licenciandos e 3 coordenadores participaram das entrevistas.

2 Tanto em 2014 como em 2015, por exemplo, os calendários das escolas e da UFV caminharam de maneira não equitativa. Isso ocorreu em função tanto de eventos específicos de cada instituição; tais como cursos de formação continuada para professores da educação básica ou atividades científicas na acadêmica, como em função da ocorrência de legítimas manifestações de paralização ou de greve, de lado a lado, em busca por melhores condições de trabalho e/ou de remuneração. Todas essas ocasiões produziram diversos desencontros entre as agendas e os calendários letivos dos estabelecimentos de ensino, cujo efeito era minorado, sempre que possível, por meio de intensas negociações entre os interesses de estudantes bolsistas, professores coordenadores e docentes da educação básica. 
entrevistado, e "de administração direta”, quando preenchido pelo próprio entrevistado. O uso de questionário é aconselhado quando se pretende conhecer uma população (modos de vida, costumes, comportamentos, valores e opiniões), analisar um fenômeno social e ainda em todos os casos em que seja necessário questionar um número elevado de pessoas sobre um determinado tema ou assunto (QUIVY, CAMPENHOUDT, 1995).

Após a aplicação dos questionários foram escolhidos seis bolsistas, a partir das perguntas respondidas, tendo como critério o maior tempo de permanência no Programa. Dessa vez o contato com os bolsistas selecionados aconteceu pessoalmente, mais como uma conversa informal, com o objetivo de aprofundar as respostas dadas às questões abordadas nos questionários aplicados, de maneira confortável e sem constrangimentos para os depoentes.

Nas entrevistas os participantes foram convidados a relatar suas experiências no cotidiano do PIBID, nas atividades desenvolvidas nas escolas, na relação com os alunos e com os professores da educação básica; as suas dificuldades em elaborar e em desenvolver atividades e projetos com e para os alunos. As entrevistas também previam interrogações sobre a relação entre a teoria estudada ao longo do curso e a prática possibilitada em sala de aula, bem como o vínculo entre essa experiência e a intenção do bolsista em atuar como docente ao término do curso. Ademais, cada um dos bolsistas pôde acrescentar informações que julgaram importantes e que não foram contempladas ao longo da conversa. Os encontros foram realizados de acordo com a disponibilidade de dias e de horários dos entrevistados, em locais agradáveis e de maneira bem natural, para que pudessem se expressar sem preocupações com o modo de falar.

Em consonância com essa fase do trabalho, foram ainda realizadas entrevistas estruturadas com os três coordenadores de área do Subprojeto Pedagogia, também docentes no Curso. As entrevistas com esses sujeitos ocorreram em condições similares àquelas desenvolvidas com os estudantes bolsistas ${ }^{3}$. Tínhamos com isso o intuito de

\footnotetext{
3 Destacamos que todas as entrevistas foram gravadas por meio de suporte eletrônico e os arquivos digitais, depois de transcriados (CALDAS, 1999, p. 96) compuseram o texto. O material encontra-se preservado com a pesquisadora e, ao término de 05 anos de conclusão do trabalho, serão inutilizados, conforme Termo de Consentimento Livre e Esclarecido (TCLE) e Cessão de Direitos Autorais (CDA) assinados entre a pesquisadora e os sujeitos depoentes, estando o uso das informações condicionadas à
} 
pesquisar e de analisar os desafios que esses coordenadores igualmente enfrentavam no âmbito do Programa. De acordo com Lakatos (1996), a entrevista:

[...] é uma das etapas mais importantes da pesquisa, exigindo tempo e cuidados. Entre eles o planejamento da entrevista, que deve ter em vista o objetivo a ser alcançado; a escolha do entrevistado, que deve ser alguém que tenha familiaridade com o tema pesquisado. (LAKATOS, 1996, p. 37).

A primeira pergunta feita foi acerca dos motivos que os levaram a se tornar coordenadores do subprojeto de Pedagogia, como forma de tentar perceber suas motivações em relação ao PIBID. Já o segundo questionamento se referia à avaliação que esses sujeitos faziam sobre o Programa, com o objetivo de identificar quais características eles atribuíam ao PIBID e como percebiam a qualidade do Programa no Subprojeto em que atuavam. Todas as questões se referiam às principais características desenvolvidas pelos coordenadores em seu trabalho e aos desafios acarretados pelo PIBID no cotidiano desses sujeitos. A última pergunta do instrumento de produção de dados se referia à relação entre os coordenadores, seus bolsistas e as escolas atendidas, na busca pela superação dos problemas que surgem no cotidiano escolar. Concluído o instrumento, abríamos espaço para que, se quisessem, acrescentassem informações não comtempladas pelas perguntas feitas.

Após a realização das entrevistas fizemos uso da transcriação, que consiste na reformulação das respostas obtidas com intuito de torná-las mais legíveis, sem, no entanto, alterar substancialmente os seus significados. Para CALDAS (1999, p. 96), essa metodologia consiste em transformar "[...] uma malha de perguntas e respostas em um texto, em uma malha ficcional". 


\section{Reflexões sobre o olhar do outro: análise dos dados construídos}

A apresentação dos dados segue com rigor a divisão entre os diferentes depoimentos dos sujeitos entrevistados. Considerando que bolsistas e coordenadores desempenhavam funções distintas, suas respostas foram analisadas separadamente. Com essa forma de organização tentamos, sempre que possível, compreender as diversas representações do Programa pelas pessoas envolvidas. Para cada indivíduo foi escolhido um nome fictício correspondente, a fim de preservar o anonimato de todos os sujeitos. $\mathrm{A}$ escolha, bastante aleatória, feita pela pesquisadora em acordo estabelecido com os entrevistados, baseou-se em nomes de personagens de algumas obras literárias. Os nomes fictícios, por sua vez, não guardam qualquer relação com características, seja das pessoas pesquisadas, seja das personagens. Decorre dessa estratégia de troca de nomes a intenção de resguardar os pontos de vista dos entrevistados, a fim de que o leitor não possa reconhecê-los a partir de suas respostas. Para além disso, também foi considerado o importante exercício da condição ética que envolve pesquisas com seres humanos e o cuidado em não expor os depoentes.

\subsection{A visão dos coordenadores de área e as suas funções}

A opção de entrevistar os coordenadores de área do subprojeto de Pedagogia surgiu do interesse em pesquisar, dentro do Programa, somente os sujeitos que tivessem vínculo com a UFV e, ao mesmo tempo, que estivessem em relação direta com as escolas atendidas pelo PIBID. Realizamos as três entrevistas nas dependências da Universidade. A primeira entrevista foi realizada no gabinete ocupado pela professora Ellie. Entre os coordenadores entrevistados ela é a que estava há mais tempo no Programa, cerca de um ano e dez meses. Ela registrou que estava feliz em saber que o foco da pesquisa era um Programa que chegava às Universidades como uma forma de valorização dos cursos e dos estudantes da Licenciatura.

Para a realização da segunda entrevista reservamos uma sala de aula nas dependências da UFV. Augustus foi entrevistado. Ele já havia atuado no PIBID antes de tornar-se professor da UFV e durante toda a entrevista demonstrou entusiasmo em 
relação à forma como o Programa funciona e, principalmente, com o fato dessa iniciativa levar os licenciandos para "o chão da escola", como revelou, antes de concluírem a graduação. Durante a entrevista o coordenador disse que estava muito otimista em relação ao PIBID.

A terceira coordenadora entrevistada era a que estava há menos tempo no Programa. Na época da entrevista ela tinha assumido a continuidade de um trabalho iniciado por outro docente da Instituição que se desligou do PIBID. Talvez por esse motivo as suas respostas tenham sido as mais sucintas. A conversa ocorreu no Laboratório de Ensino do Departamento de Educação da UFV. A coordenadora Alice deu respostas curtas e diretas às perguntas feitas, apesar de não ter se negado a responder nenhuma das questões.

A primeira pergunta feita aos coordenadores foi: "Quais motivos o/a levaram a se tornar coordenador/a do subprojeto de Pedagogia no PIBID?" De maneira geral os três coordenadores entrevistados demonstraram em suas respostas que o interesse em participar do PIBID estava vinculado à oportunidade de supervisionar e de orientar a entrada de estudantes, futuros professores, no ambiente escolar antes da conclusão do curso. Pelos depoimentos, foi possível perceber que o contato com a escola era de grande importância para os estudantes de Licenciatura, por possibilitar vivências que tenderiam a ser significativas para esses sujeitos, segundo os coordenadores. Além disso, para eles, o Programa significava a chance de que os estudantes relacionassem e aplicassem toda a teoria estudada na prática. Essa concepção demonstra que o PIBID era compreendido pelos professores coordenadores como uma forma de os bolsistas estabelecerem relação entre todo o aporte teórico disponível (nas aulas dos próprios coordenadores) e as experiências vivenciadas, pelos licenciandos, no cotidiano escolar.

Pesquisa de Gatti e Nunes (2009), que investigou propostas curriculares das Licenciaturas em todo o Brasil, mostrou que os cursos se mantêm focados em modelos idealizados de alunos e de professores, com predominância dos estudos teóricos e das disciplinas de formação genérica em relação à formação para a prática docente. A relação teoria-prática é quase ausente nas dinâmicas curriculares, bem como estudos sobre a escola, o que indica uma formação de caráter abstrato e desarticulada do contexto de 
atuação do professor. As práticas educativas na escola e nas salas de aula são o cerne da educação escolar e, portanto, deveriam ser a do trabalho do professor. Os três coordenadores pesquisados reconheceram no Programa a chance da aproximação entre a formação na educação superior e o trabalho desenvolvido nas escolas. Um dado interessante nas respostas foi que, coincidentemente, a coordenadora Alice decidiu fazer parte do Programa por um objetivo similar ao que levou ao desenvolvimento da nossa pesquisa: conhecer os desafios do PIBID. De fato, a escola e seus sujeitos são um campo fértil para o surgimento de desafios e conhecê-los tende a ser o primeiro passo para promover a sua superação.

O segundo questionamento buscava identificar quais as representações que os coordenadores teriam em relação à qualidade do PIBID em seu Subprojeto. Assim, a pergunta foi: “Como você avalia a qualidade do Programa no Subprojeto Pedagogia?”.

Em resposta a essa pergunta, Ellie fez questão de frisar que a sua opinião sobre a qualidade do Programa era restrita ao seu grupo de orientandos bolsistas, já que o Subprojeto do Curso de Pedagogia na UFV era subdivido entre os quatro docentes que o coordenavam. Então, em relação ao seu grupo, ela avaliou o PIBID como uma espécie de “atualização do contexto escolar", tendo em vista que considerava que as ações desenvolvidas por meio do Programa “oxigenavam as práticas pedagógicas e se apresentam como novas perspectivas para os professores e alunos das escolas atendidas". Para ela, os bolsistas eram peça fundamental nesse contexto ao possibilitarem que os professores explorassem novas formas de trabalho, além do fato de terem um "olhar de fora desse espaço, não tão impregnado de vícios como o dos professores que, na maioria das vezes, já estão inseridos nesse universo por um longo período de tempo" e que, "engolidos pelo sistema”, não teriam condições de estar sempre atualizando suas práticas.

Por sua vez, Augustus fez questão de frisar que a qualidade do Programa em seu Subprojeto era "mérito de suas bolsistas, que desempenham seus trabalhos com afinco e prazer pelo que fazem". Alice não discorreu muito sobre essa pergunta, apenas fez menção à "relação entre a aproximação de escolas públicas e universidades" e ao fato de 
essa oportunidade de ser bolsista aproximar o estudante do universo escolar, preparando-o para sua futura profissão, fatores que seriam propiciados pelo PIBID.

A terceira questão teve o objetivo de conhecer as funções desenvolvidas pelos coordenadores. Embora o Subprojeto fosse de um único curso de Licenciatura, o de Pedagogia, ele estava dividido entre os quatro docentes. Isso fazia com que cada uma dessas divisões tivesse características distintas e, consequentemente, o trabalho de cada um também fosse realizado de forma diferente. Nesse sentido a questão foi: "Cite algumas das principais características de seu trabalho com o PIBID”.

Apesar das diferenças de orientações e de escolhas dos coordenadores dentro do mesmo Subprojeto, houve consenso em relação ao reconhecimento da principal função de orientação do trabalho de seus bolsistas. Segundo os depoentes, a coordenação seria responsável por articular o diálogo entre a teoria e a prática, embasando o desenvolvimento das atividades realizadas no âmbito do Programa. Para Ellie, suas orientações ao grupo de orientandos bolsistas caminhavam na direção de que cada estudante fosse sempre capaz de trabalhar com base no que teriam de melhor a oferecer para os alunos, os professores e as escolas da Educação Básica. A responsabilidade que a coordenadora coloca como sua poderia indicar um apoio importante para os bolsistas de iniciação à docência, pois muitas vezes não é possível realizar um trabalho eficiente por uma escolha equivocada da metodologia, por exemplo. Logo, quando existe a consciência de qual a maneira que potencializa as atividades a serem desenvolvidas, o trabalho pedagógico tende a ser mais eficaz.

Pudemos perceber nos depoimentos dos coordenadores uma grande conexão entre o que eles reconheciam como suas funções e efetivamente aquilo que estava definido no Regimento do Programa Institucional de Bolsas de Iniciação à Docência como parte de suas responsabilidades. A Resolução n. 13/2014 apresenta como deveres específicos de coordenadores ações como a de orientar e de acompanhar, pessoalmente, nas escolas envolvidas, e conjuntamente com os supervisores, a atuação dos bolsistas de iniciação à docência, elaborando o cronograma anual de ações a serem desenvolvidas e coordenando e orientando os licenciandos durante sua a execução. Obviamente esses deveres precisavam ser diluídos na parceria entre os coordenadores com os supervisores, 
professores tutores da educação básica. Assim, na UFV, cada coordenador do Subprojeto Pedagogia promovia reuniões periódicas com os licenciandos e os supervisores, conforme cronograma previamente estabelecido por cada grupo. A partir dos dados obtidos nas entrevistas foi possível perceber que os coordenadores de área do PIBIDPedagogia não só conheciam as suas atribuições como as colocavam em prática em seu dia a dia, o que favorecia o desenvolvimento do trabalho realizado.

Em outra questão do roteiro de entrevistas, convidamos os coordenadores a falar sobre os desafios que enfrentavam em seu cotidiano, tocando assim em um dos objetivos iniciais específicos da nossa pesquisa. A pergunta: "Quais são os principais desafios acarretados pelo Programa em seu dia a dia como coordenador?" visava não apenas conhecer, mas também analisar como os professores coordenadores lidavam com os desafios do PIBID.

As respostas obtidas nessa pergunta indicaram que cada coordenador apresentava uma visão bastante distinta acerca dos desafios enfrentados. A coordenadora Ellie indicou a falta de recursos financeiros como um grande desafio, principalmente quando essa ausência atingia o atendimento de escolas distantes do centro da Cidade. Tendo em vista que os bolsistas não contavam com ajuda financeira do Programa para se deslocar até as instituições onde atuavam, talvez fosse de se esperar que a maioria dos discentes, de fato, optasse por cumprir a carga horária em escolas mais próximas. Essa opção acabava negligenciando parte do objetivo do PIBID, qual seja, o de inserir os licenciandos no cotidiano de escolas da rede pública de educação. Isso porque, a partir do momento em que condições financeiras ajudavam a determinar a escolha de algumas escolas em detrimento de outras, escolas rurais, ou mesmo aquelas distantes do centro de Viçosa, por exemplo, deixavam de ser atendidas. Essas escolas muitas vezes apresentavam precárias condições de funcionamento, dadas as condições materiais e objetivas a que estavam expostas, fruto, sobretudo, do lugar em que se encontravam na configuração espacial do mapa da cidade, distantes da circulação de pessoas, mercadorias e bens culturais ou de serviço.

Em contraponto a esse desafio, gerado pela falta de recursos, a coordenadora ressaltou que, nessa situação, um lado positivo seria o caráter formativo, de certa forma 
"imposto aos bolsistas". Ao se depararem com a escassez de recursos, os bolsistas precisavam recorrer a maneiras alternativas para levarem adiante o seu trabalho. Ao citar que os desafios do PIBID seriam os mesmos da educação pública no Brasil, a coordenadora reconhecia a fragilidade do sistema de ensino brasileiro, que encara, diariamente, inúmeros percalços. Outra preocupação da mesma coordenadora esteve relacionada à falta de produção teórica no âmbito do Programa. Apesar de os bolsistas produzirem planos de aula, projetos pedagógicos e relatórios mensais sobre as atividades realizadas, os dados construídos a partir dessas atividades não eram organizados, sistematizados e analisados. Para ela não havia "um aproveitamento, nesse sentido, do material que os estudantes produzem".

Em consonância à preocupação dessa coordenadora, Silva (2007) enfatiza que nos últimos anos os educadores vêm encontrando grandes dificuldades em trabalhar com a pesquisa na área educacional. Um dos motivos dessas dificuldades pode ser a falta de aprimoramento na pesquisa e no fato de que ela não estaria inserida no processo educacional e na prática pedagógica de docentes da educação básica Nesse contexto, o PIBID poderia ser o local onde essas dificuldades seriam superadas.

Por fim, a coordenadora fez menção às relações sociais estabelecidas no contexto escolar. Sendo a escola um ambiente em que circulam os mais variados costumes, diferentes crenças ou valores, seria comum que essas relações gerassem conflitos e impasses. De acordo com Curonici e McCulloch (1999), a escola se caracteriza por sua complexidade, não é definida apenas pelo grande número de pessoas reunidas, mas também pelo elevado número de interações que nela se desenvolvem.

Tal como Ellie, Augustus também fez menção à falta de recursos e às dificuldades geradas por essa situação no desenvolvimento de seu trabalho junto aos seus bolsistas de iniciação à docência. O que diferiu a sua resposta foi a preocupação do docente em saber lidar com as diferentes pessoas com as quais ele se relacionava, em decorrência de sua função no PIBID. Em meio a tantos afazeres e a tantas tarefas assumidas pelos coordenadores, esse não era um dado levantado como hipótese por nossa pesquisa. A sensibilidade demonstrada pelo coordenador, a de pensar nos bolsistas e nos supervisores das escolas de educação básica, teria forte relação com o que Batitucci 
(2002) caracterizou como sintonia entre o "eu" e o "outro", com a capacidade de colocar-se no lugar da outra pessoa, captar as mensagens e sinais do outro, não fazer julgamentos prévios, ajustar-se e disponibilizar-se ao outro.

Diferente dos outros dois coordenadores Alice expressou como o seu maior desafio a falta de tempo para se dedicar ao PIBID, em decorrência das demais atividades que realiza na Universidade.

A última questão: "Você considera que existe uma parceria com as escolas atendidas pelo Subprojeto, os bolsistas e os coordenadores para aplicar as estratégias definidas pelo PIBID?" visava a identificar e compreender a relação estabelecida entre a escola e os sujeitos do Programa, na intenção de superar os desafios que também seriam de responsabilidade da instituição escolar e não apenas e necessariamente do Subprojeto.

Ellie foi clara ao ressaltar que essa parceria entre as escolas e o seu grupo de orientação no Subprojeto-Pedagogia inexistia. Segundo ela, o trabalho era "fragmentado e dicotômico, de modo que não acontece uma produção conjunta entre as escolas e o PIBID”. Já o coordenador Augustus apresentou uma leitura completamente diferente. Ele considerou que o seu trabalho funcionava em conjunto com as escolas e afirmou que os entes envolvidos, "escolas e Universidade, compreendem as adversidades e trabalham juntos para superá-las". Por fim, a coordenadora Alice relatou que essa responsabilidade seria uma função apenas sua e, preferiu não mencionar como é sua relação com as escolas atendidas por seu subprojeto.

As formas como Ellie, Augustus e Alice apresentaram compreender a relação entre a Universidade e a Educação Básica podem ser analisadas a partir das experiências de cada docente em sua atuação como coordenador do Subprojeto-Pedagogia. Experiências essas que podem representar, entre outras coisas, o fruto do tempo de atuação no magistério do ensino superior público, o resultado do tempo de trabalho com o PIBID ou ainda a aderência da área específica de formação e de atuação de cada um deles no Curso de Pedagogia, por exemplo. Além disso, também as relações estabelecidas entre cada coordenador e seu grupo de bolsistas e entre seu grupo e as escolas também poderiam 
explicar as diferentes repostas. Entretanto, apesar da aparente divergência nos depoimentos, ressaltamos que o conjunto do material de entrevistas indica que os coordenadores possibilitaram entender melhor como representavam as suas funções e quais ações desenvolviam no Programa. De modo geral talvez possamos afirmar que os coordenadores fizeram reflexões muito positivas e parecidas em relação ao Programa e demonstraram isso ao citar o PIBID como um meio de valorização dos cursos e estudantes de Licenciaturas nas universidades públicas brasileiras. Todos também foram unânimes em apresentar o PIBID tanto como uma política de formação docente relevante para os estudantes como uma política de garantia de permanências nos cursos de licenciatura, visto que muitos bolsistas necessitavam do apoio financeiro para garantir a continuidade de seus estudos. Igualmente, os três coordenadores ressaltaram a importância do Programa ao proporcionar uma relação de ordem prática entre a Educação Básica e o Ensino Superior. Ainda foi possível notar que todos acreditavam muito no trabalho dos bolsistas e que tinham preocupação em orientá-los e acompanhálos no desenvolvimento de suas atividades. Ter a possibilidade de atuar em um Programa que aproxima a Universidade das instituições básicas é, de fato, visto como uma maneira de valorizar a profissão docente e de contribuir para a melhora da qualidade da educação no processo de ensino-aprendizagem desenvolvido nas instituições escolares.

\subsection{Os bolsistas de iniciação à docência e suas representações sobre o} programa

O contato com os bolsistas de iniciação à docência, diferente dos coordenadores, foi dividido em duas etapas. Primeiramente contatamos os 63 bolsistas por meio de correio eletrônico, convidando-os a responder a um questionário online. 54 questionários foram respondidos e devolvidos pelos bolsistas, todos do sexo feminino, estudantes, em sua grande maioria, do quarto e sexto períodos do Curso de Pedagogia. Todas atuantes no Programa há cerca de um ano. Selecionamos uma amostra de 10\% dos questionários respondidos e assim escolhemos cinco bolsistas. Como critério de escolha, entramos em contato para o agendamento de entrevista com aquelas pessoas que possuíam mais 
tempo no PIBID, entre um ano e um mês e um ano e nove meses, por acreditar que o tempo de experiência pudesse lhes ter possibilitado vivenciar situações diversas, experiências de planejamento e de execução de diferentes metodologias. Assim como no caso dos coordenadores também atribuímos nomes fictícios às licenciandas.

Os encontros com as bolsistas ocorreram em diferentes salas do Departamento de Educação da Universidade, nos meses de setembro e de outubro de 2015 e tiveram duração média de quarenta minutos cada. As entrevistas também foram gravadas e transcriadas.

A primeira pergunta da entrevista foi: "Como você descreve a sua experiência no PIBID levando em consideração o cotidiano escolar e as relações estabelecidas nesse contexto?".

Pelas respostas ficou claro como a escola foi representada pelas bolsistas como um lugar que proporcionava as mais diversas relações e situações para os sujeitos que a frequentavam. A bolsista Hazel destacou que não havia "uma receita de como construir experiências na escola simplesmente porque a escola é um organismo pulsante que muda a cada dia", que demandaria "coisas diferentes, em dias diferentes, de pessoas diferentes." Para ela, ser inserido nesse ambiente gerou muitas dúvidas e questionamentos, momentos de insegurança "por não saber como lidar com os acontecimentos, com as pessoas, com as exigências e as maneiras de funcionamento do cotidiano da escola". Hazel informou que somente a prática e o convívio puderam tornar essa relação mais clara, no sentido de situar as bolsistas e a escola para a presença mútua desses sujeitos nesse ambiente, otimizando as relações e fazendo delas a base para o desenvolvimento eficaz e significativo de seus respectivos trabalhos.

Também buscamos conhecer as dificuldades enfrentadas por essas bolsistas no interior da escola, pretendendo justamente identificar os desafios que surgiam no dia a dia dos bolsistas.

As estudantes elencaram muitos desafios em suas respostas de forma que foi possível identificar pontos distintos em cada uma. As bolsistas Hazel, Alaska e Anne se referiram às dificuldades geradas pela falta de recursos financeiros no Programa, relacionando a isso o desafio em planejar e em executar as atividades pedagógicas com 
os alunos. De acordo com as bolsistas, a escassez de materiais didáticos reduzia as possibilidades de trabalho. Outra questão levantada por parte das entrevistadas consistiu na dificuldade de pensar atividades significativas para os alunos. Essa preocupação ficou evidente e foi fácil notar que esse talvez fosse o maior desafio enfrentado por elas, tendo em vista a grande diversidade de alunos com os quais trabalhavam e considerando que cada um desses alunos tinha um tempo e uma maneira distintas de aprender. Por fim, as entrevistadas Bella e Anne destacaram como desafio as suas dificuldades em saber separar a relação com os alunos em espaços diferentes como o de dentro e o de fora da escola. Ambas se mostraram muito comovidas ao relatar que muitas crianças se encontravam inseridas em contextos de vulnerabilidade e que elas carregavam as suas dificuldades culturais, familiares e/ou financeiras para o interior da escola. Bella e Anne destacaram que essa sensibilidade precisou ser dosada a fim de que conseguissem se distanciar dos problemas e das demandas dos alunos e conseguissem continuar atuando no Programa sem se deixarem abater pelas histórias de vida dessas crianças.

Em outra questão buscamos compreender qual relação as bolsistas estabeleciam entre a teoria que estudavam/estudaram, ao longo do Curso de Pedagogia, e a prática propiciada pelas ações desenvolvidas no PIBID. Assim, o questionamento foi: “Existe relação entre a teoria estudada no seu Curso de Pedagogia e a prática vivenciada no PIBID? Qual seria a contribuição do Programa para a sua formação?".

A questão obteve respostas unânimes quanto à relação teórico-prática entre o curso de Pedagogia e as vivências propiciadas pelo PIBID. Todas as bolsistas ressaltaram a importância do Programa como local para colocarem em prática aquilo que estudaram e que conheceram nas aulas da graduação, bem como destacaram a relevância de todas essas referências para embasar as suas ações nas escolas. Ficou claro que para elas havia um forte elo entre o PIBID e a formação, como se um funcionasse como complemento do outro, já que para desenvolver um trabalho eficaz no Programa seria necessário conhecer e compreender o referencial teórico produzido no campo da Educação. Para Lima (2001), a prática pela prática e o emprego de técnicas sem a devida reflexão pode reforçar a ilusão de que há uma prática sem teoria. Nessa mesma linha de pensamento, Gómez (2000, p. 85) interpreta a prática pedagógica como "uma rede viva de troca, criação e 
transformação de significados". Ou seja, a prática pedagógica de um professor deve ser capaz de orientar, de preparar, de motivar e de efetivar as trocas entre os alunos e o conhecimento científico, de modo que eles construam e reconstruam os seus significados, sendo indispensável para isso uma base teórica sólida e consistente.

Com o objetivo de verificar se a experiência vivenciada no PIBID confirmaria a intenção futura das bolsistas em trabalhar como docentes ao final do curso de Pedagogia, perguntamos: “A experiência no PIBID reforça a sua intenção de atuar na profissão docente ao término do curso?".

De maneira geral as licenciandas disseram que pretendem ser professoras após a conclusão do Curso e consideraram que o PIBID confirmava e reforçava essa escolha. Ao longo das entrevistas ficou evidente que o Programa era representado, pelas bolsistas, como uma prévia daquilo que em breve assumiriam como profissionais. Nesse contexto o PIBID seria uma grande oportunidade ao favorecer que as estudantes vivenciassem antecipadamente os conflitos e os desafios da docência. E, principalmente, ao oportunizar o exercício da superação dos conflitos e dos desafios. Talvez seja possível afirmar que as bolsistas entendiam o PIBID como a chance de "conhecer a escola por dentro, dessa vez com mais tempo e com mais envolvimento do que nos estágios curriculares", como revelou Hazel. Em resumo, constatamos que, apesar das adversidades, a opção por ser professora era, naquele momento, uma certeza para as bolsistas, ainda que elas indicassem a consciência das dificuldades e dos impasses que possivelmente iriam vivenciar.

Em outro momento perguntamos: "Você considera que o PIBID está alcançando os seus objetivos, como por exemplo, a valorização do magistério e a melhora da qualidade da educação básica?". Os dados obtidos a partir desse questionamento foram muito sucintos e atribuímos a isso o fato de acreditar que talvez as bolsistas talvez não tivessem muito conhecimento acerca dos objetivos teóricos do PIBID. Assim, talvez não tivessem condições de discorrer a fundo sobre a pergunta. Apesar disso, todas elas disseram acreditar que o Programa estava cumprindo com os objetivos aos quais se propunha; destacando principalmente, tal como os professores coordenadores, o fato de o PIBID possibilitar a inserção dos licenciandos nas escolas de educação básica. 
Por fim, a última questão, relacionada às atividades das bolsistas como estudantes: "Qual a sua maior dificuldade como bolsista, do ponto de vista institucional, como parte de uma política pública?”

Assim como ao responder sobre os desafios que enfrentam em suas experiências no cotidiano escolar, as bolsistas elencaram inúmeras situações. O mesmo aconteceu quando às questionamos a respeito do papel duplo que exerciam sendo estudantes da Universidade e bolsistas no Programa. Entre as dificuldades as bolsistas Hazel e Anne destacaram as ações formativas planejadas pelo setor institucional do PIBID na UFV, que muitas vezes eram agendadas sem antecedência e em horários que coincidiam com outras atividades exercidas pelas licenciandas. Para Hazel e Bella o fato de o Programa não conceder férias também era um impasse, já que independente das atividades da Universidade elas precisavam estar presentes em Viçosa para cumprir a carga horária obrigatória do PIBID. Anne também destacou como desafio a falta de comunicação e de retorno entre os bolsistas, os coordenadores de área e os demais sujeitos envolvidos no Programa, o que dificultaria o feedback entre tudo o que os bolsistas produziam e o que era feito com todo esse material ao ser enviado para o setor institucional na UFV. As bolsistas Alaska e Verônica destacaram a falta de recursos que afetava o PIBID. Elas argumentaram que o valor recebido não compensava mais a permanência no Programa, já que seus gastos como estudantes eram maiores que o valor pago pela bolsa. Elas também relataram que, em alguns casos, a atuação na escola gerava ainda gastos particulares pagos pelas próprias estudantes.

A partir da análise de cada uma das respostas concedidas foi possível notar que as representações que as bolsistas têm sobre o Programa são muito similares. Em suas respostas elas abordaram pontos comuns, ainda que fizessem parte de grupos diferentes no Subprojeto Pedagogia. Também pudemos constatar que em muitos momentos as respostas fornecidas pelas bolsistas se aproximavam das respostas obtidas durante as entrevistas com os coordenadores. Como, por exemplo, as respostas em relação à falta de recursos para dar continuidade aos projetos e o caráter formativo que atribuem ao PIBID. Consideramos que essa semelhança tenha relação com o fato de que os coordenadores eram aqueles com quem os bolsistas tinham mais contato. É notável que, 
assim como os coordenadores, as bolsistas também têm uma visão bastante positiva do PIBID e de sua atuação no Programa, apesar de todas as adversidades que enfrentavam.

\section{Pensamentos à guisa de conclusões}

Nossa pesquisa aponta que as representações criadas a partir das experiências vivenciadas pelos sujeitos inseridos no ambiente escolar por meio do PIBID de Pedagogia, da Universidade Federal de Viçosa, são muito próximas. Na maioria das vezes elas se traduzem em concepções similares acerca das perspectivas, dos desafios e dos caminhos traçados, na intenção de aperfeiçoar as ações desenvolvidas pelo PIBID.

Durante o caminho percorrido, perante as diversas fontes de informações sobre o tema e a cada transcriação de entrevista, fomos encontrando dados que corroboram os resultados mais expressivos indicados pela literatura mais geral do campo de estudos e pesquisas da Formação Docente: a noção de que novas identidades profissionais estão sendo formadas. E que essas novas identidades profissionais docentes encontram espaço e representação no PIBID, na noção de que diversas, diferentes (e muitas vezes conflitantes) relações se desenvolvem no interior das escolas, momentos formativos e desafiantes que rodeiam a prática profissional. Com base no referencial teórico e nas análises feitas a partir dos instrumentos de produção de dados, podemos concluir que, assim como a Educação, também o Programa é recheado de impasses e de dificuldades. A relação estabelecida entre o ensino superior e a educação básica nos fez perceber que ainda há muito que se afinar, sendo sempre necessário estar atento às mudanças e às adversidades que possam surgir, pois o espaço escolar é bastante instável, assim como as condições que possibilitam a realização do trabalho dos sujeitos responsáveis pelo processo de ensino-aprendizagem que se desenvolvem neste contexto.

Também foi possível constatar, a partir das entrevistas, que existe uma íntima relação entre a teoria estudada no curso de Pedagogia e a prática proporcionada pela experiência no PIBID. As bolsistas de iniciação à docência e os coordenadores de área reconheciam essa relação e a valorizavam como uma das principais características do Programa. A inserção de estudantes no Programa servia para situar os bolsistas no 
contexto escolar, preparando-os para um devir profissional, aquilo que estaria por vir. Além de possibilitar essa experiência, de acordo com as bolsistas entrevistadas, o PIBID também confirmaria uma de suas intenções: a de que os estudantes bolsistas, de fato, seguissem a carreira profissional docente após a conclusão do curso inicial de formação.

\section{Referências}

ARAÚJO, Jussara de Loiola; BORBA, Marcelo de Carvalho. Construindo pesquisas coletivamente em educação matemática. In: BORBA, Marcelo de Carvalho; ARAUJO, Jussara de Loiola (Orgs). Pesquisa qualitativa em educação matemática. Belo Horizonte: Autêntica, 2004.

BATITUCCI, Márcio Dayrrell. Equipes 100\%. São Paulo: Pearson Education do Brasil, 2002.

BONDÍA, Jorge Larrosa. Notas sobre a experiência e o saber de experiência. In: Revista Brasileira da Educação, Rio de Janeiro, n. 19, Jan./abr., 2002.

CALDAS, Alberto Lins. Transcriação em história oral. Revista do Núcleo em História Oral, São Paulo, n. 01, p. 71-79, nov., 1999.

CARDOSO, Frederico Assis. A identidade de professores homens na docência com crianças: homens fora do lugar? 154f. 2004. Dissertação (Mestrado em Educação) Universidade Federal de Minas Gerais, Curso de Pós-graduação em Educação da, Belo Horizonte/MG, 2004.

CONSELHO DE ENSINO, PESQUISA E EXTENSÃO. Resolução 13/2014, do CEPE, de 14 de agosto de 2014: aprova o regimento do programa institucional de bolsas de iniciação à Docência -PIBID. Legislação Federal e Marginália. Brasília, 2014.

CURONICl, Chiara; MCCULLOCH, Patrícia. Psicólogos e professores: um ponto de vista sistêmico sobre as dificuldades escolares. São Paulo: EDUSC, 1999.

FREIRE, Paulo. Pedagogia da autonomia: saberes necessários à prática educativa. 34. ed. São Paulo: Paz e Terra, 1996.

GATTI, Bernadete Angelina; BARRETO, Elba Siqueira de Sá; ANDRÉ, Maria Eliza Dalmazo de Afonso. Políticas docentes no Brasil: um estado da arte. Cadernos de Pesquisa, Brasília, UNESCO, v. 42, n.145, jan./apr., 2011. 
GATTI, Bernadete Angelina; BARRETTO, Elba Siqueira de Sá. Professores: aspectos de sua profissionalização, formação e valorização social: relatório de Pesquisa. Brasília: Unesco, 2009.

GATTI, B. A.; NUNES, M. M. R. (Orgs.) Formação de professores para o ensino Fundamental: estudo de currículos das licenciaturas em Pedagogia, Língua Português, Matemática e Ciências Biológicas. São Paulo: FCC/DPE, 2009. (Coleção Textos FCC, v. 29).

GÓMEZ, Angel. I. Pérez. Ensino para a compreensão. In: SACRISTÁN, José Gimeno; GÓMEZ, Angel. I. Pérez. Compreender e transformar o ensino. 4. ed. Porto Alegre: Artmed, 2000, p. 67-98.

JOHNSON, Richard. O que é, afinal, estudos culturais? In: SILVA, Tomaz Tadeu da (Org. e trad.). $O$ que é, afinal, estudos culturais? ${ }^{4}$ Belo Horizonte: Autêntica, 1999, p. 9-131.

LAKATOS, Eva Maria; MARCONI, Marina de Andrade. Técnicas de pesquisa. 3.ed. São Paulo: Atlas, 1996.

LIMA, Maria Socorro Lucena. A hora da prática: reflexões sobre o estágio supervisionado e ação docente. 2. ed. Fortaleza: Edições Demócrito Rocha, 2001.

LUNA, Sérgio Vasconcelos de. Planejamento de pesquisa: uma introdução. 2. ed. São Paulo: EDUC, 1999.

MALHOTRA, Naresh. Pesquisa de marketing: uma orientação aplicada. 4. ed. Porto Alegre: Bookman, 2006.

MINAYO, Maria Cecília de Souza. (Org.). Pesquisa social: teoria, método e criatividade. 16.ed. Petrópolis: Vozes. 1994.

NELSON, Cary, et al. Estudos Culturais: uma introdução. In: SILVA, Tomaz Tadeu da (Org). Alienígenas na sala de aula: uma introdução aos estudos culturais em educação. 2. ed. Petrópolis: Vozes, 2003, p. 7-38.

QUIVY, Raymond; CAMPENHOUDT, Luc Van. Manual de investigação em ciências sociais. Lisboa: Gradiva. 1995.

SCHÖN, Donald. Educando o profissional reflexivo: um novo design para o ensino e a aprendizagem. Porto Alegre: Artmed, 2000.

\footnotetext{
4 Trata-se de capítulo homônimo ao livro.
} 
Programa institucional de bolsa de iniciação à docência: perspectivas e desafios no âmbito do subprojeto 